The localization of the liver specific antibody on the cell membrane and around the nucleus of hepatic cells is similar to the observation by Nairn et al. ${ }^{5}$. The results experimentally confirm a previous postulation that during its binding with specific proteins of hepatic cells $3^{\prime}$-DAB acts as a hapten and changes the specificity of the liver specific antigen ${ }^{1}$. But whether repeated binding of the liver specific antibody by hepatic cells leads to adaptive loss of their organ specific antigen and their subsequent escape into malignancy, however, remains to be demon. strated experimentally.

Department of Experimental Pathology

$$
\text { H. N. Green }
$$$$
\text { T. GHOSE* }
$$

and Cancer Research,

University of Leeds.

* Present address: Department of Pathology, University of Aberdeen. 1 Green, H. N., Nature, 192, 1201 (1961).

${ }^{2}$ Mansi, W., Nature, 181, 1289 (1958).

${ }^{3}$ Nairn, R. C., Fluorescent Protein Tracing (E. and S. Livingstone, Ltd. Edinburgh and London, 1962)

${ }^{4}$ Ghose, T., Nairn, R. C., and Fothergill, J. E., Nature, 196, 1108 (1962). 'Nairn, R. C., Richmond, H. G., MoEntegart, M. G., and Fothergill, J. E., Brit. Med. J., ii, 1335 (1960).

\section{A Substance in Blood Lethal for Candida albicans}

WHILE performing investigations on the intra-leucocytic survival of Candida, we found that Candida tropicalis survived in whole human blood but Candida albicans did not. Results were similar for cell-free plasma and serum. In these investigations, $0 \cdot 1 \mathrm{ml}$. of an inoculum of $10^{7}$ Candida cells was added to $1 \mathrm{ml}$. of serum or plasma in siliconized tubes. The Candida-serum mixture was rotated at $37^{\circ} \mathrm{C}$ for $24 \mathrm{~h}$. At 0,6 , and $24 \mathrm{~h}$, Candida populations were determined by pour plate enumeration techniques. The serum was considered lethel for Candida if fungal census was reduced at least 10 -fold at the 6- or 24-h periods when compared with the 0 -h count.

So far, the lethal factor has been present in 20/20 sera from healthy adults less than 50 years of age, in 20/24 persons over 50, in each of 11 specimens from normal children and in $7 / 8$ cord bloods.

The candidacidal substance is active after heating to $70^{\circ} \mathrm{C}$ for $1 \mathrm{~h}$. It survives 2 -week refrigeration at $4^{\circ} \mathrm{C}$ and indefinitely if frozen at $-20^{\circ} \mathrm{C}$. Serum activity is lost by 24-h dialysis through 'Cellophane' or collodion membranes against water, saline, or solutions containing physiological concentrations of potassium, magnesium, or calcium. After dialysis through collodion, the substance can be demonstrated in the dialysate. Serum ultra. filtrates obtained by passing specimens through $a$ 'Cellophane' membrane at 300 lb. pressure ('Araflow' ultra. filters, Applied Research Assoc., New York) have no candidacidal activity. The dialysis and ultrafiltration investigations suggest the molecular weight of the substance is between 10,000 and 20,000 . If the weight were less than 10,000 it should have appeared in the ultrafiltrate. If it were more than 20,000 , it could not have passed through the dialysis bags.

Addition of trypsin, $15 \mu \mathrm{g} / \mathrm{ml}$. or 1 per cent ethyl alcohol to serum or plasma immediately before adding Candida cells results in loss of activity.

Addition of glucose in concentrations up to $1,000 \mathrm{mg}$ per cent, hydrocortisone $1-1,000 \mu \mathrm{g} / \mathrm{ml}$, penicillin $1-50$ $\mu / \mathrm{ml}$., chloramphenicol $1-50 \mu \mathrm{g} / \mathrm{ml}$. or tetracycline $1-50$ $\mathrm{\mu g} / \mathrm{ml}$. did not diminish the activity of normal sera.

The substance appears to have impressive specificity. It is active against Candida albicans and Candida stellatoidea but not against other Candida species or other yeasts such as Cryptococcus neoformans or Saccharomyces cereviseae. It is not readily adsorbed; thus, in vitro incubation at $37^{\circ} \mathrm{C}$ (with constant agitation) for up to $24 \mathrm{~h}$ with live or heat-killed Candida cells does not modify the netivity of normal plasma.
Sera which have no fungicidal activity retain opsonic capacity for Candida cells. When $10^{6}$ Candida cells are added to normal whole human blood, virtually the entire inoculum is found in polymorphonuclear colls after 30 -min rotation at $37^{\circ} \mathrm{C}$. Results are the same for whole blood from patients whose serum and plesme have no candida. cidal activity. In patients with mucocutaneous or systemic candidiasis who do not possess the factor, agglutinating antibody titres of $1: 64-1: 128$ have been found, indicating that the candidacidal substance is not related to this type of antibody.

Starch column electrophoresis investigations using large samples of normal human plasma with a barbital buffer show that the substance is present in both the $\alpha$ - and $\beta$ globulin fractions. Neither the albumin nor the $\gamma$-globulin fraction is active. The $\alpha$-globulin fraction is 5-10 times more active than the $\beta$-globulins, suggesting that the factor migrates primarily with $\alpha$-globulins. Starch column electrophoresis also permits the separation of candidacidal activity from serum-induced production of germ tubes and pseudomycelia by Candida cells. The germ tube and pseudomycelium transformation is related primarily to the presence of the albumin fraction.

At present the significance of this substance is not clear. It does not appear related to the inhibitory substance of Lorincz, Priestley, and Jacobs', which is heat-labile, or that of Roth and Goldstein ${ }^{2}$, which is not dialysable and is far more active against other Candida species than against $C$. albicans. Furthermore, serum specimens which do not possess candidacidal activity do have inhibitory capacities when an inoculum of $10^{3}$ is added and the Candida-serum mixture incubated for $24 \mathrm{~h}$ at $37^{\circ} \mathrm{C}$ with constant rotation.

Preliminary work on specimens from various patient groups suggest that there is a moderate to marked reduction in the factor in a substantial proportion of persons with cirrhosis, hepatitis, diabetic azotæmia, non-diabetic renal disease with azotrmia, and in those with either mucocutaneous or systemic candidiasis. The percentage of persons possessing the factor is slightly reduced among groups of patients with diabetes (without azotæmia) and with disseminated carcinoma.

The experiments summarized here suggest that the substance, which is presumably a small protein or poly. peptide, may be important in determining the degree of susceptibility to focal and generalized Candida albicans infections.

DONALD B. Louria

Cornell (Second) Medicel Division, Bellevue Hospital, New York.

${ }^{1}$ Lorincz, A. L., Priestley, J. O., and Jacobs, P. H., J. Invest, Dermat., 31,15 (1958).

${ }^{2}$ Roth, F. J., and Goldstein, M. I., J. Invest. Dermat., 36, 383 (1961).

\section{RADIOBIOLOGY}

\section{Spring Precipitation and the Strontium-90 Contamination of Wheat in the Semi-arid Regions of Idaho and Montana}

Strontrum-90 is one of the long-lived radionuclide constituents of fall-out that can be expected as a contaminant of cereal grains for long periods of time. Much of the strontium- 90 content of wheat grain is believed to result from direct floral interception rather than to uptake from previously contaminated soils ${ }^{1,2}$. It has also been reported that over extendod time periods soils experiencing greater annual precipitation accumulated more strontium-90 than did soils of drier regions ${ }^{3}$. From these premises it would seem that wheat growing in regions experiencing marked spring precipitation should exhibit higher strontium -90 contents than wheat grown in regions with relatively weak spring precipitation. An inspection of 